\title{
Establishment of the Initial Sandplay Picture System for Chinese Young Internet Addicts: Based on Valence Assessment of Normal Adolescents
}

\author{
Ying Ge1*, Junyu Huo ${ }^{1,2}$, Jingyi Yuan'1, Huiyong Fan ${ }^{3}$ \\ ${ }^{1}$ Key Laboratory of Emotion and Mental Health in Chongqing, Chongqing University of Arts and Sciences, Chongqing \\ Collaborative Innovation Center for Brain Science, Chongqing, China \\ ${ }^{2}$ College of Transportation Engineering, Tongji University, Shanghai, China \\ ${ }^{3}$ College of Education and Sciences, Bohai University, Jinzhou, China \\ Email: `gy8620@163.com, huojun_yu@163.com,chinaxiaofan@126.com
}

How to cite this paper: Ge, Y., Huo, J.Y., Yuan, J.Y. and Fan, H.Y. (2021) Establishment of the Initial Sandplay Picture System for Chinese Young Internet Addicts: Based on Valence Assessment of Normal Adolescents. Health, 13, 273-282.

https://doi.org/10.4236/health.2021.133022

Received: January 24, 2021

Accepted: March 13, 2021

Published: March 16, 2021

Copyright $\odot 2021$ by author(s) and Scientific Research Publishing Inc.

This work is licensed under the Creative Commons Attribution International License (CC BY 4.0).

http://creativecommons.org/licenses/by/4.0/

\begin{abstract}
To develop the initial sandplay picture system for Chinese young internet addicts (ISPSCYIA) for the diagnosis and testing studies on internet addiction, 22 pictures were selected from the used pictures of initial sandplay in existing research results of initial sandplay of Chinese young Internet addicts. 54 normal adolescents were recruited to evaluate the valence of the pictures on a nine-point scale in terms of clarity, pleasure and arousal. Results were shown that there were no significant differences between addiction pictures and nonaddiction pictures in clarity, while there were significant differences in pleasure and arousal, as the scores of non-addiction pictures were higher. Correlation analysis indicated that there was obvious positive correlation among clarity, pleasure and arousal of addiction pictures \& non-addiction pictures. The coefficients of internal consistency reliability and split-half reliability of 22 pictures' scores exhibited both over 0.90 . ISPSCYIA has proved typical and distinctive through valence assessment, which could be preliminarily applied to measure the characteristics of Chinese adolescents' internet addiction.
\end{abstract}

\section{Keywords}

Chinese Adolescents, Internet Addiction, Initial Sandplay, Picture System, Valence Assessment

\section{Introduction}

With its penetration of social life, the internet has been the important path to Co first authors: Ying Ge, Junyu Huo; Co corresponding authors: Junyu Huo, Huiyong Fan. 
get information, the bridge for communication and the entertainment platform for current adolescents. Until December of 2020, there are 989 million Chinese netizens, among which 339 million are youth netizens, accounting for $34.4 \%$ [1]. However, internet brings not only convenience but also hazards: the youth lacking self-control and discrimination are addicted to the internet for a long period, so a special problem is caused during their key growth time-Internet Addiction Disorder. Goldberg set a precedent for Internet Addiction Disorder study, and Young launched the research and named the symptom as "Internet Addiction Disorder" (IAD) [2]. Diagnostic and Statistical Manual of Mental Disorders (DSM-V) indicates that "online game addiction disorder" is a kind of mental and behavioral disorder caused by repeatedly overusing the internet, represented by strong desire for reusing the internet and withdrawal reaction when internet use is stopped or reduced, and possibly accompanied by psychiatric and physical symptoms [3]. In 2018, "gaming disorder" is listed in "mental, behavioral or neurodevelopmental disorders" of International Classification of Disease (ICD-11) by World Health Organization (WHO) for the first time, including online games and video games [4]. As most Chinese internet addictions are online game addictions [5], this definition can basically cover the connotation of internet addiction. Therefore, China Youth Health Education Core Information and Interpretation issued by the National Health Commission of PRC clearly defines IAD as the impulsive behavior to use the internet without addictive substances, manifesting obvious harm to one's study, occupation and social function [6]. And the time of duration is an important criterion of the diagnosis of IAD. Generally, it is confirmed when related behaviors continue for at least 122 months [6]. Existing research shows that the IAD rate among Chinese adolescents is 10\% [7].

Screening, testing and diagnosis of addicts are tasks of top priority for IAD research. Researchers have devoted themselves to compiling and revising the assessment instruments for internet addiction to build standardized and objective tools. At present, in addition to DSM-V and ICD-11, traditional structured questionnaires and scales are still mainly adopted in IAD testing. For example, Young K.S., based on the diagnostic criteria for pathological gambling in DSM, compiled eight diagnostic criteria for internet addiction [8]. It is widely used and has good reliability and validity, but it doesn't have Chinese norms. Chen et al. from Taiwan developed Chinese Internet Addiction Scale (CIAS) and Revised Chinese Internet Addiction Scale (CIAS-R) which have 26 items, taking university students from Taiwan as samples. The scale has good reliability and validity [9]. Lei et al. compiled Adolescent Pathological Internet Use Scale (APIUS) consisting of 17 items, which is suitable for adolescents [10]. Chen \& Zhao made a multivariate generalizability analysis of the Chinese Internet Addiction Scale to prove its good reliability and validity [11].

A projective test is an evaluation method that makes conclusions on the basis of clinical experience and theories through examinees' psychological works such as paintings, stories and imagination, so as to indirectly assess examinees' psy- 
chological characteristics, personality structure and motivation and attitudes. It was first put forward by Murray in his Explorations in Personality [12]. Especially, it is not influenced by cultural background and does not require a specific situation, and it gives insight into the personal unconscious. The stimulants and instructions applied to a projective test are unstructured. The biggest difference with a questionnaire test is its implicitness and generalizability. The most typical projective test is Rorschach Inkblot Test and Thematic Apperception Test (TAT).

Sandplay therapy was developed by Dora Kalff, a Jungian analyst. Based on analytical psychology, it is a projective therapy and psychotherapy integrated with play therapy [13]. In sandplay therapy, a player presents invisible mental facts appropriately and symbolically by using sand, a sand tray and miniatures of related figures or objects, to express the player's experience in the prelinguistic stage and blocked mental energy, so as to gain integrated development in the game [14]. Sandplay therapy can be applied to treatment and diagnosis, and it has a history of nearly a century, introduced to China in 1990s [15]. Its empirical study seeks objective support for itself by verifying its standardization and effectiveness. Aoki studied the retest reliability of the sandplay technique to prove the difference in emotion regulation between the juvenile delinquent group and the normal group [16]. Fan et al. verified the effectiveness of sandplay therapy in psychotherapy for young children, integrating questionnaires and interviews [17].

The initial sandplay is the first model made by a player, having special significance in the sandplay technique. It not only indicates the relationship between consciousness and unconsciousness of players to reflect the essence of personal problems and difficulties and achieve self-projection, but also provides players with clues and directions to solve problems [13]. Therefore, researchers summarized the characteristics in initial sandplay of different groups, such as obsessive-compulsive disorder [18], depressive disorder [19], somatization [19], borderline personality disorder [20] and positive psychological symptoms [21], proved the effectiveness of sandplay therapy, promoted the standardization of sandplay and laid a foundation for sandplay works to be primary diagnostic indexes and sandplay therapy to be applied in clinical diagnosis and assessment.

In summary, questionnaires and scales have been mostly employing in the screening, diagnosis and assessment of IAD. However, as a behavioral addiction involving many complicated factors of the mental-physical structure, the essential problem of IAD might be unavailable to be revealed comprehensively by structured questionnaires and scales, and need further supplement and improvement in other ways. Due to its inherent projectiveness, sandplay proves itself suitable to test IAD. At the moment, the research of IAD sandplay largely focuses on psychological intervention [22] [23] [24]. Ge et al. conducted preliminary study on the characteristics in initial sandplay of Chinese young internet addicts [25], but there have not been research results of objective assessment for the 
picture system of IAD initial sandplay.

Therefore, establishing a standardized initial sandplay picture system might help researchers choose stimulating materials that are more suitable for research, improving the comparability of experimental results. Based on pictures of the characteristics in initial sandplayay of Chinese young Internet addicts in the research of Ge et al. [25], this research establishes a standardized picture system of IAD initial sandplay through the assessment of pictures to provide empirical evidence of reliability and validity for the research on IAD sandplay.

\section{Method}

\subsection{Participants}

In this study, 300 adolescents of a senior high school in Chongqing, China, were recruited to complete the Adolescent Pathological Internet Use Scale (APIUS); and then 54 normal participants from subjects within the normal score ranges (an average score less than 3.15 points) of APIUS were randomly selected on a voluntary basis to participate in the pictures valence assessment. Participants were between 15 and 16 years of age $(\mathrm{M}=15.68, \mathrm{SD}=0.66), 26(48.2 \%)$ were male and $28(51.8 \%)$ were female. The inclusion criteria were: 1) Fluent communication; 2) No family history of mental illness in three generations of either the father's or mother's family; 3) Within the normal score ranges(an average score less than 3.15 points) of the Adolescent Pathological Internet Use Scale (APIUS); 4) Exclusive of persons with neurological disorder, serious physical disease and hearing or visual impairment; 5) Never attending the sandplay experiment.

This APIUS consists of 38 questions in 6 dimensions, namely, salience, mental alteration, social comfort, tolerance, compulsive internet use and negative outcomes, which adopts 5-points based self-assessment scale, ranging from "definitely no" to "absolutely yes". The KMO index and Cronbach's Alpha coefficient of the scale were 0.940 and 0.948 respectively; the coefficient of retest reliability was 0.857 . According to APIUS, those whose average scores are equal or exceed 3.15 points are labeled as "internet-addicts", while those whose average scores are less than 3.15 points belong to "non-addicts" [9].

\subsection{Materials}

Sixty pictures collected in the research of the characteristics in initial sandplay of Chinese young Internet addicts were chosen and edited in Photoshop depending on uniform specifications, namely $19.6 \times 11.4 \mathrm{~cm}$ (size), $4000 \times 3000$ (pixel) and 96 pixels/inches (resolution ratio). In addition, the pictures had consistent contrast, color and brightness.

\subsection{Assessment Methods and Procedures}

The pictures of initial sandplay were rich in content and colorful, so the clarity of pictures was put as the first consideration in establishing a standardized pic- 
ture system of IAD initial sandtray, thus to guarantee all pictures selected clearly present the appearance of initial sandtray. Next, the pictures elicited personal responses, so it was necessary to consider emotional factors of the pictures. In light of the emotion theory raised by Osgood et al. [26] [27] and the valence assessment method of pictures used by Wang et al. [28], two dimensions, pleasure and arousal, were also chosen in this research. In the end, pictures were scored through self-assessment in terms of three aspects, namely clarity, pleasure and arousal.

The experimental procedure was processed by E-Prime software to display pictures in a random order. Participants assessed the valence of the pictures in a nine-point assessment scale in accordance with clarity, pleasure and arousal. Participants managed the whole assessment process by themselves, with an intermission of $100 \mathrm{~ms}$ after the assessment of each picture. The procedure was divided into three rounds. After the assessment of all pictures in one dimension, there was a break for 1 minute, and then participants began the assessment of the next dimension. In the assessment, "1" was the minimum value of each dimension (low clarity, low pleasure and low arousal level) and "9" was the maximum value of each dimension (high clarity, high pleasure and high arousal level).

\section{Results}

\subsection{Picture Clustering}

According to the research of Ge et al. [25] in which the characteristics of 60 participants (30 internet addicts and 30 non-addicts) in initial sandplay were checked in terms of the quantity of sand tools and the theme of sandtray, internet addicts preferred military sand tools to those featuring daily life or nature and presented themes about division and confusion rather than themes on integration and penetration. Pictures of initial sandplay were selected into the library based on the result. That is, the pictures for internet addicts might contain more military sand tools and less sand tools featuring daily life or nature, and more themes about division and confusion and less themes on integration and penetration. Non-addiction pictures were exactly the opposite. Finally, a total of 22 pictures ( 11 for internet addicts and 11 for non-addicts) were added to the library.

\subsection{Descriptive Statistics and T-Test}

The results of descriptive statistics and paired-samples $t$-test (Table 1): There was no significant difference in clarity between the two types of pictures $(t=$ $1.295, p=0.201)$, while there were significant differences in pleasure $(t=-2.481$, $p=0.016)$ and arousal $(t=-2.202, p=0.032)$. Meanwhile, the two-dimensional diagram was drawn to show the results of addiction pictures and non-addiction pictures in the two-dimensional space with pleasure and arousal. The results revealed that 54 normal adolescents had higher arousal and pleasure levels for non-addiction pictures than for addiction pictures (Figure 1). 
Table 1. Results of descriptive statistics for two types of pictures.

\begin{tabular}{cccc}
\hline Type & Dimension & N & $M \pm S D$ \\
\hline \multirow{3}{*}{ Addiction pictures } & Clarity & 54 & $5.89 \pm 1.84$ \\
& Pleasure & 54 & $5.23 \pm 1.53$ \\
& Arousal & 54 & $4.94 \pm 1.46$ \\
\hline \multirow{2}{*}{ Non-addiction pictures } & Clarity & 54 & $5.70 \pm 2.01$ \\
& Pleasure & 54 & $5.88 \pm 1.91$ \\
& Arousal & 54 & $5.45 \pm 1.91$ \\
\hline
\end{tabular}

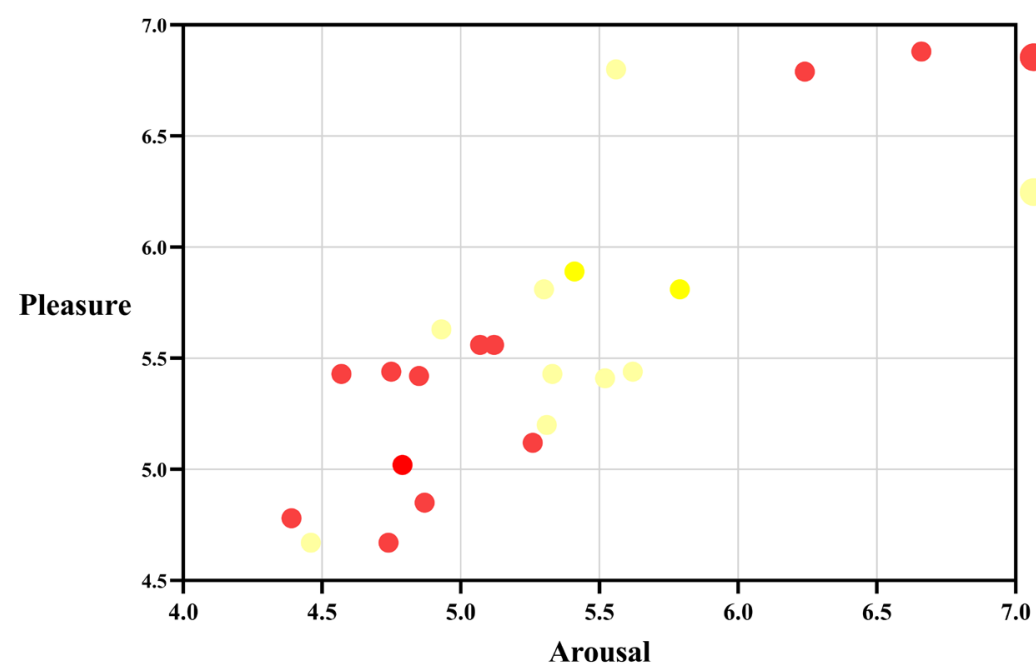

Internet addicts's sandplay picture

Non-Internet addicts's sandplay picture

Figure 1. Two-dimensional diagram of pleasure and arousal for two types of pictures.

Table 2. Correlation analysis matrix of each dimension in two types of pictures.

\begin{tabular}{cccc}
\hline & Clarity VS Pleasure & Clarity VS Arousal & Pleasure VS Arousal \\
\hline Addiction pictures & $0.78^{* * *}$ & $0.66^{* * *}$ & $0.87^{* * *}$ \\
Non-addiction pictures & $0.79^{* * *}$ & $0.77^{* * *}$ & $0.90^{* * *}$ \\
\hline
\end{tabular}

Note: ${ }^{*} p<0.05,{ }^{* *} p<0.01,{ }^{* * *} p<0.001$.

\subsection{Correlation Analysis}

In order to further the analysis for the correlation of the three dimensions, the Pearson's correlation coefficient of the three dimensions in the two types of pictures was calculated (Table 2). The results showed that there was a significant positive correlation between the two types of pictures in each dimension, and the correlation coefficients of each dimension of addiction pictures were lower than those of the non-addiction pictures.

\subsection{Internal Consistency Reliability and Split-Half Reliability}

The 22 pictures were scored in a nine-point assessment scale concerning clarity, pleasure and arousal. The coefficients of internal consistency reliability were 0.924 , 0.961 and 0.958 ; the coefficients of split-half reliability are $0.785,0.823$ and 0.915 . 


\section{Discussion}

The establishment of the picture system was based on the pictures in the research of the characteristics of 60 subjects (30 for each group) in initial sandplay by Ge et al. [25]. The selection criteria were as below: addiction pictures should contain more military sand tools and less sand tools featuring daily life or nature, and more themes about division and confusion and less themes on integration and penetration, while non-addiction pictures were exactly the opposite. Eventually, a total of 22 pictures ( 11 for internet addicts and 11 for non-addicts) were added to the library. Then, 54 normal Chinese adolescents were recruited to score the valence of the 22 pictures regarding clarity, pleasure and arousal.

From the results of descriptive statistics and paired-samples $t$-test, it could be found that: with respect to clarity, there was no difference between addiction pictures and non-addiction pictures, showing that the two types of pictures had the same clarity and the same picture attributes (color, contrast ratio and saturation, etc.). Addiction pictures and non-addiction pictures had significantly different scores in pleasure and arousal, and the scores of addiction pictures were lower than those of non-addiction pictures. It displayed that the negative information (military sand tools and themes of division and confusion) of addiction pictures aroused discomfort of participants, so normal adolescents' pleasure and arousal for those pictures were weakened [25]. It also exhibited that normal participants easily distinguished the two types of pictures and tended to choose non-addiction pictures. Two-dimensional diagram of pleasure and arousal is consistent with the results above.

The results of correlation analysis demonstrated that there was an obvious positive correlation between the two types of pictures in each dimension, and the correlation coefficients of each dimension of addiction pictures were lower than those of the non-addiction pictures. It indicated that the sensitivity of non-addicted normal participants to the addiction pictures was weaker than their sensitivity to non-addiction pictures. Clarity is a condition which makes picture recognition available. Only on this basis, could the individual realize in-depth recognition and processing of pictures. The clearer the pictures of the two types were, the more clearly persons could notice the emotional information conveyed by the pictures, so their emotional feelings to different pictures were fully aroused. Therefore, it was in line with the actual life that there was a positive correlation between clarity, pleasure \& arousal. The positive correlation between pleasure and arousal manifested that the higher the pleasure level was, the higher the arousal level was. Normal participants had pleasant emotion facing positive information, but when negative information was added, the pleasure went down.

On the results of descriptive statistics and correlation analysis, normal participants indicated a difference in the recognition of addiction pictures and of non-addiction pictures, having a lower sensitivity to addiction pictures, which exhibited the distinction between the two types. Additionally, the coefficients of internal consistency reliability in this research were all above 0.9 , which pre- 
sented that participants gave relatively consistent scores to the 22 pictures of initial sandplay in the same dimension, and the pictures were highly homogeneous. The results of split-half reliability again showed that 54 participants' assessment was consistent, and the internal assessment of the pictures was stable.

All the results were identical to the scale testing results. The normal participants selected by the scale had lower sensitivity to addiction pictures than to non-addiction pictures, which indicated that the pictures selected are typical and distinctive. In conclusion, the developed ISPSCYIA is effective to evaluate the characteristics of Chinese adolescents' IAD in a preliminary stage with good recognition degree and psychological measurement attribution.

\section{Future Work}

The present study has established an initial sandplay picture system for young internet addicts in China, which can be preliminarily applied to the projection assessment and research of the characteristics of internet addiction in Chinese adolescents. Nevertheless, in this study, we only recruited relatively few participants for the purpose of valence assessment. In the future, we will encourage more practitioners to adopt the ISPSCYIA, and build a sample database of the usability of the picture system, which can include more data provided by various valence evaluators for further reporting more reliability and validity evidences.

\section{Conflicts of Interest}

The authors declare no conflicts of interest regarding the publication of this paper.

\section{References}

[1] China Internet Network Information Center (CNNIC) (2021) The 47th China Statistical Report on Internet Development. http://www.cac.gov.cn/2021-02/03/c 1613923423079314.htm

[2] Young, K.S. (1998) Internet addiction: The Emergence of a New Clinical Disorder. Cyber Psychology \& Behavior, 1, 237-244. https://doi.org/10.1089/cpb.1998.1.237

[3] American Psychiatric Association (APA) (2013) Diagnostic and Statistical Manual of Mental Disorders (DSM-V). 5th Edition, American Psychiatric Publishing, Washington DC. https://doi.org/10.1176/appi.books.9780890425596

[4] World Health Organization (2018) International Classification of Diseases 11th Revision. https://icd.who.int/en

[5] Tao, R., Ying, L., Yue, X.-D., et al. (2007) Analysis and Intervention of Internet Addiction. Shanghai People's Publishing House, Shanghai.

[6] Chinese Center for Health Education (2018) China Youth Health Education Core Information and Interpretation. Health Guide, 6, 42-46.

[7] Liu, B.-Z. and He, B.-B. (2019) New Dynamic and Trends in the Research on Internet Addiction among Chinese Adolescents. Journal of Chongqing University of Posts and Telecommunications (Social Science Edition), 31, 80-89.

[8] Johansson, A. and Gotestam, K.G. (2004) Internet Addiction: Characteristics of a Questionnaire and Prevalence in Norwegian Youth (12 - 18 Years). Scandinavian 
Journal of Psychology, 45, 223-229.

https://doi.org/10.1111/j.1467-9450.2004.00398.x

[9] Chen, S.-H., Weng, L.-J., Su, Y.-J., et al. (2003) Development of a Chinese Internet Addiction Scale and Its Psychometric Study. Chinese Journal of Psychology, 45, 279-294. https://doi.org/10.1037/t44491-000

[10] Lei, L. and Yang, Y. (2007) The Development and Validation of Adolescent Pathological Internet Use Scale. Acta Psychologica Sinica, 39, 688-696. https://doi.org/10.1037/t53624-000

[11] Chen, W. and Zhao, S.-Y. (2016) A Multivariate Generalizability Analysis of the Chinese Internet Addiction Scale (Revise). Studies of Psychology and Behavior, 14, 95-99.

[12] Murray, H.A. (1938) Explorations in Personality. Oxford University Press, New York.

[13] Doa, K. (2003) Sandplay: A Psychotherapeutic Approach to the Psyche. Temenos Press, London.

[14] Shen, H.-Y., Chen, K. and Gao, L. (2005) History and Theory of Sandplay Therapy. Psychological Development and Education, 21, 124-128.

[15] Lai, X.-L., Chao, D.-R. and Ding, C.-W. (2010) Application and Research Status of Sandplay Therapy. China Journal of Health Psychology, 18, 754-756.

[16] Aoki, S. (1981) The Retest Reliability of the Sandplay Technique. British Journal of projective Psychology and Personality Study, 26, 25-33.

[17] Fan, G.-P., Gao, L. and Li, J.-X. (2003) Exploring the Theory of Sandplay and Researching How to Use it in the Kindergarten. Psychological Exploration, 23, 51-54.

[18] Zhang, W., Zhang, R.-S. and Jiang, Z.-L. (2011) Qualitative Study of Sandplay Productions of Undergraduates with Obsessive-Compulsive Symptom. Chinese Journal of Clinical Psychology, 19, 553-557.

[19] Tan, J.-F., Shen, H.-Y. and Li, H.-Z. (2012) A Research on the Characteristics in Initial Sandtray of the Depression Symptoms. Psychological Science, 35, 999-1003.

[20] Li, J.-X., Xiang, J.-J. and Shen, H.-Y. (2009) Characteristics in Initial Sandtray of Patients with Borderline Personality Disorder. Chinese Mental Health Journal, 23, 280-285.

[21] Tan, J.-F., Shen, H.-Y. and Li, H.-Z. (2010) A Research on the Characteristics in Initial Sandtray of the Positive Psychological Symptoms. Chinese Journal of Clinical Psychology, 18, 472-474.

[22] Mo, W.-H. and Peng, Z.-W. (2007) Effect of Sandplay Therapy in IAD of Middle School Students. Chinese Journal of Behavioral Medicine and Brain Science, 16, 836-837.

[23] Hao, Q.H. (2011) College Students' Internet Addiction in Light of Psychoanalysis Theory. Studies in Ideological Education, 8, 73-77.

[24] Zhang, J.-X. and Wang, P.-P. (2015). An Empirical Comparison of Three Typical Psychotherapies in College Students' Internet Addiction. Psychological Exploration, 35, 557-560.

[25] Ge, Y. and Huo, J.-Y. and Wang, X.-Q.. (2018) Sandplay Therapy among Adolescents with Internet Addiction. Chinese Journal of School Health, 39, 383-386.

[26] Tucker, D.M., Hartry-Speiser, A., Mcdougal, L., Luu, P. and Degrandpre, D. (1999) Mood and Spatial Memory: Emotion and Right Hemisphere Contribution to Spatial Cognition. Biological Psychology, 50, 103-125. 
https://doi.org/10.1016/S0301-0511(99)00005-8

[27] Kemp, A.H., Gray, M.A., Eide, P., Silberstein, R.B. and Nathan, P.J. (2002) SteadyState Visually Evoked Potential Topography during Processing of Emotional Valence in Healthy Subjects. NeuroImage, 17, 1684-1692.

https://doi.org/10.1006/nimg.2002.1298

[28] Wang, Y. and Luo, Y.-J. (2005) Standardization and Assessment of College Students' Facial Expression of Emotion. Chinese Journal of Clinical Psychology, 13, 396-398. 